\title{
FOXO3a orchestrates glioma cell responses to starvation conditions and promotes hypoxia-induced cell death
}

\author{
DANIEL P. BRUCKER ${ }^{1,2,4^{*}}$, GABRIELE D. MAURER ${ }^{1 *}$, PATRICK N. HARTER $^{3,4}$, \\ JOHANNES RIEGER ${ }^{1,2}$ and JOACHIM P. STEINBACH ${ }^{1,2,4}$
${ }^{1}$ Dr. Senckenberg Institute of Neurooncology, Goethe University Hospital, Frankfurt; ${ }^{2}$ Department of Neurology, Eberhard Karls University Hospital, and Hertie Institute for Clinical Brain Research, Tübingen;
${ }^{3}$ Institute of Neurology (Edinger Institute), Goethe University Hospital; ${ }^{4}$ German Cancer Consortium (DKTK), Partner Site Frankfurt/Mainz, Frankfurt, Germany

Received August 8, 2016; Accepted October 21, 2016

DOI: 10.3892/ijo.2016.3760

\begin{abstract}
Forkhead box O (FOXO) transcription factors are homeostatic regulators adjusting diverse cellular processes crucial for metabolism and survival. In gliomas, FOXOs have been shown to modulate cell death, proliferation and differentiation. Here, we investigated the role of FOXO3a in human malignant gliomas with special regard to starvation conditions. Expression of FOXO3a increased with WHO grade and was accentuated in the perinecrotic niche, colocalizing with hypoxia-inducible factor $1 \alpha$ (HIF1 $\alpha$ ) expression. FOXO3a was upregulated in hypoxia and translocation of FOXO3a from the cytoplasm to the nucleus was induced by serum starvation, pharmacological inhibition of protein kinase $\mathrm{B}(\mathrm{PKB})$ and hypoxia. Overexpression of FOXO3a
\end{abstract}

Correspondence to: Professor Joachim P. Steinbach, Dr. Senckenberg Institute of Neurooncology, Goethe University Hospital, Schleusenweg 2-16, D-60528 Frankfurt, Germany

E-mail: joachim.steinbach@med.uni-frankfurt.de

*Contributed equally

Abbreviations: 2-NBDG, 2-(N-(7-nitrobenz-2-oxa-1,3-diazol-4-yl) amino)-2-deoxyglucose; BIM, Bcl-2-like protein 11; BrdU, 5-bromo2'-deoxyuridine; CBP, cAMP response element-binding (CREB)-binding protein; CITED2, CBP/p300 interacting transactivator with Glu/Asp rich carboxy-terminal domain 2; DAPI, 4',6-diamidino-2-phenylindole; GFP, green fluorescent protein; GLUT1, glucose transporter 1; HIF-1 $\alpha$, hypoxia-inducible factor-1 $\alpha$; IDH1, isocitrate dehydrogenase 1; MnSOD2, manganese superoxide dismutase; ROS, reactive oxygen species; $\mathrm{SCO} 2$, $\mathrm{SCO} 2$ cytochrome $c$ oxidase assembly protein; SDHA, succinate dehydrogenase complex, subunit A; SEM, standard error of the mean; shRNA, short hairpin ribonucleic acid; siRNA, small interfering ribonucleic acid; SLC16A3, solute carrier family 16, member 3 (monocarboxylic acid transporter 4); TGF- $\beta$, transforming growth factor- $\beta$; TIGAR, TP53-induced glycolysis and apoptosis regulator; TP53, tumor protein p53; TRAIL, tumor necrosis factor-related apoptosis-inducing ligand; VEGF, vascular endothelial growth factor

Key words: Forkhead box O3a, metabolism, glioma, hypoxia, glucose induced tumor necrosis factor-related apoptosis-inducing ligand (TRAIL) expression and resulted in spontaneous cell death. Knockdown of FOXO3a (shFOXO3a), on the one hand, enhanced the sensitivity of glioma cells towards $\mathrm{H}_{2} \mathrm{O}_{2}$ under normoxia. On the other hand, it decreased consumption of glucose and oxygen, resulting in improved survival during glucose and oxygen deprivation. Mechanistically, in shFOXO3a cells, hypoxia-response element reporter activity, as well as the expression of common HIF1 $\alpha$ target genes, was increased, suggesting disinhibited HIF1 $\alpha$ signaling. However, glucose transporter 1 (GLUT1) expression was inversely regulated, and this may have been caused by an upregulation of TP53 in shFOXO3a cells. These data reveal a novel role of FOXO3a-dependent gene regulation in the complex adaptive responses of gliomas towards starvation signals. Strategies that target FOXO3a function may directly or indirectly alter glioma cell behavior and viability in the hypoxic niche.

\section{Introduction}

The Forkhead box O (FOXO) family of transcription factors maintains homeostasis under conditions of, e.g., oxidative stress, starvation and growth factor deprivation (reviewed in refs. 1,2). By regulating the expression of genes such as Bcl-2-like protein $11(B I M)$, Fas ligand (FasL), transforming growth factor- $\beta(T G F-\beta)$,tumornecrosisfactor-relatedapoptosis-inducing ligand (TRAIL), CBP/p300 interacting transactivator with Glu/Asp rich carboxy-terminal domain 2 (CITED2), manganese superoxide dismutase $(\mathrm{MnSOD})$, isocitrate dehydrogenase 1 (IDH1) and survivin $(3,4)$, it controls important cellular functions, such as survival, cell growth, differentiation, senescence, oxidative stress resistance and metabolism. First considered tumor suppressors, FOXOs also exhibit pro-tumoral functions in a context-dependent manner. On the one hand, FOXO activity promotes cell differentiation, cell cycle arrest and apoptosis and is inhibited by the activation of well characterized oncogenic signaling pathways such as phosphatidylinositol 3-kinase (PI3K)-protein kinase B (PKB) $(5,6)$. On the other hand, FOXO factors have been described to be involved in resistance to anticancer drugs, maintenance of leukemia-initiating cells (7) and colon cancer metastasis (8). 
So far, four FOXO family members have been identified in humans: FOXO1, FOXO3a, FOXO4 and FOXO6. Although they all bind to the motif 5'-TTGTTTAC-3' and may act redundantly, they also display distinct functions and some of these differences are attributed to their tissue-specific expression pattern. Especially FOXO3a has been associated with longevity and diseases such as cancer and was shown to be activated in response to various stress stimuli. Function and activity of FOXO transcription factors are substantially controlled by post-translational modifications, including phosphorylation, acetylation, methylation and ubiquitination, and binding protein partners. Their subcellular localization modified by environmental stimuli is considered of major importance (9-11). The regulation of nuclear-cytoplasmic FOXO shuttling is complex and influenced by multiple signaling pathways. Frequently activated in malignant glioma (12), PKB phosphorylates FOXO in the nucleus and thus enables FOXO binding to $14-3-3$ proteins, leading to its nuclear export and inactivation.

In glioma, FOXO factors have been shown to induce differentiation of glioblastoma stem-like cells (13) and to inhibit tumor growth (14). They can suppress $M Y C$ expression, induce apoptosis, decrease glycolysis and inhibit glucose uptake (15). However, in glioblastoma stem cells with functional tumor protein $\mathrm{p} 53$ (TP53), FOXO proteins have recently been demonstrated to be essential for maintaining stemness and survival after ionizing radiation combined with dual inhibition of PI3K and mechanistic target of rapamycin (mTOR) (16).

Reprogramming of metabolism is one of the evolving hallmarks of cancer (17), and has received increasing attention during the last decade. Current treatment strategies for malignant gliomas continue to achieve little success. The metabolic versatility of glioma cells that adapt to conditions of recurrent deficiency in nutrients and/or oxygen may be paramount for this $(18,19)$. Histologically, glioblastomas are characterized by rapid proliferation and extensive neo-vascularization. Structurally and functionally abnormal blood vessels are unable to meet the demands for nutrients and oxygen. This ends up in fluctuating local hypoxia that again encourages angiogenesis, invasion and metabolic alterations (20), including an increased dependency on glycolysis. Hypoxia-inducible factors (HIFs) here play substantial roles. Jensen et al found that FOXO3a was activated in hypoxia as a target gene of HIF1 and that a knockdown of FOXO3a increased cell death in hypoxia both in $\mathrm{HeLa}$ and in U2OS cells. FOXO3a was required for hypoxic suppression of mitochondrial mass, oxygen consumption and reactive oxygen species (ROS) production (21).

The present study sought to expand our understanding of FOXO3a function in glioma biology. While in glioma cells, primarily antitumor activities of $\mathrm{FOXO} 3 \mathrm{a}$ have been described, inhibition of the upstream regulator $\mathrm{PKB}$, and thereby activation of FOXO3a function, confers protection against hypoxia-induced cell death (22). Therefore, we aimed to elucidate the function of FOXO3a under starvation conditions that are commonly found in the glioma microenvironment.

\section{Materials and methods}

Reagents. PCR primers and small interfering ribonucleic acids (siRNAs) were purchased from Sigma-Aldrich (St. Louis, MO,
USA) or Qiagen (Hilden, Germany). siRNA sequences, Sigma-Aldrich: CITED2, sense r(CCAGGUUUAACAACUC CCA)dTdT, antisense r(UGGGAGUUGUUAAACCUGG) dTdT and sense r(CCUAAUGGGCGAGCACAUA)dTdT, antisense r(UAUGUGCUCGCCCAUUAGG)dTdT; FOXO3a, sense r(GAAUGAUGGGCUGACUGAA)dTdT, antisense r(UUCAGUCAGCCCAUCAUUC)dTdT. siRNA sequences, Qiagen: AllStars negative control, FOXO1, sense r(GGA GGU AUG AGU CAG UAU A)dTdT, antisense r(UAUACUGACU CAUACCUCC)dAdT, sense r(UCAUGUCUUGAUAAGU UAA)dTdT, antisense r(UUAACUUAUCAAGACAUGA) dGdG and sense r(CCAAGUAGCCUGUUAUCAA)dTdT, antisense r(UUGAUAACAGGCUACUUGG)dTdT; FOXO3a, sense r(GAAUGAUGGGCUGACUGAA)dTdT, antisense r(UUCAGUCAGCCCAUCAUUC)dAdG, sense r(GGAACG UGAUGCUUCGCAA)dTdT, antisense r(UUGCGAAGCAU CACGUUCC)dGdG and sense r(GAUUCAUGCGGGUCC AGAA)dTdT, antisense r(UUCUGGACCCGCAUGMUC) dGdA. Metafectene Pro was acquired from Biontex (Munich, Germany), Attractene from Qiagen,DEVD-amc ( $N$-acetyl-AspGlu-Val-Asp-aminomethyl-coumarin) and Z-VAD-fmk ( $N$-benzyloxycarbonyl-Val-Ala-Asp-fluoromethylketone) from Bachem (Weil am Rhein, Germany) and recombinant human TRAIL from PeproTech (Rocky Hill, NJ, USA). Antibodies used were anti-actin (polyclonal goat anti-human, sc1616; Santa Cruz Biotechnology, Inc., Santa Cruz, CA, USA), anti-FOXO3a (immunohistochemistry, monoclonal rabbit anti-human, clone EP1949Y), anti-FOXO3a (western blot analysis, monoclonal rabbit anti-human, clone EPR1950) (both from Epitomics, Burlingame, CA, USA), anti-HIF1 $\alpha$ (BD Transduction Laboratories, San Jose, CA, USA), anti-phospho-AKT Ser473 (polyclonal rabbit anti-mouse), anti-phospho-FOXO1 Ser256 (polyclonal rabbit anti-human) (both from Cell Signaling Technology, Danvers, MA, USA), anti-phospho-FOXO3a Thr32 (polyclonal rabbit anti-human; Upstate, Merck Millipore, Darmstadt, Germany), anti-phospho-TP53 Ser15 (polyclonal rabbit anti-human; Cell Signaling Technology) and anti-TP53 (monoclonal mouse anti-human; Calbiochem, Merck Millipore). The 3HRE-pTK-luc reporter construct was a generous gift from Berra et al (23). The adenoviral FOXO constructs (24), plasmids encoding FOXO3a, FOXO3a-A3 and FOXO3a-green fluorescent protein (GFP) (25), the plasmid encoding FOXO1-GFP (26) and the constructs FOXO3a-TM and FOXO3a-TM-ER-dDB (27) were kindly provided by colleagues from other laboratories. The TP53-luc construct was purchased from Agilent Technologies (Santa Clara, CA, USA).

Cell culture. LNT-229 human malignant glioma cells were kindly provided by $\mathrm{N}$. de Tribolet. Cells were cultured in Dulbecco's modified Eagle's Medium $(4,500 \mathrm{mg} / 1$ glucose; Sigma-Aldrich), supplemented with $10 \%$ fetal calf serum (FCS; PAA, Pasching, Austria), $2 \mathrm{mM}$ glutamine, $100 \mathrm{IU} / \mathrm{ml}$ penicillin and $100 \mu \mathrm{g} / \mathrm{ml}$ streptomycin, at $37^{\circ} \mathrm{C}$ and $5 \% \mathrm{CO}_{2}$. For some experiments, glucose was added to serum- and glucose-free medium to give final concentrations of 2 or $5 \mathrm{mM}$. A Binder CB53 incubator (Binder, Tuttlingen, Germany) was used for experiments in hypoxia.

FOXO3a and HIF1 gene silencing. To silence FOXO3a gene expression, short hairpin RNA (shRNA) sequences were cloned 
into the pSUPER-puro vector (28). FOXO3a shRNA sequences were sense GATCCCCGGAACGTGATGCTTCGCAATT CAAGAGATTGCGAAGCATCACGTTCCTTTTTGGAAA, antisense TCGATTTCCAAAAAGGAACGTGATGCTTCG CAATCTCTTGAATTGCGAAGCATCACGTTCCGGG and sense GATCCCCGAATGATGGGCTGACTGAATTCAAG AGATTCAGTCAGCCCATCATTCTTTTTGGAAA, antisense TCGATTTCCAAAAAGAATGATGGGCTGACTGA ATCTCTTGAATTCAGTCAGCCCATCATTCGGG, respectively. The scrambled shRNA sequence has been published previously (29). Glioma cells were transfected using Attractene, stable cell lines were generated by puromycin selection (5 $\mu \mathrm{g} / \mathrm{ml})$. LNT-229 cells stably transfected with an shRNA targeting HIFl $\alpha$ and its control (Sima) as well as HIF $2 \alpha$ and $H I F 1 \alpha-H I F 2 \alpha$ double-knockdown LNT-229 cells were a kind gift of Henze et al (30).

Growth and viability assays. A crystal violet staining assay was used for the determination of cell density. The dye was resolubilized in $0.1 \mathrm{M}$ sodium citrate, the absorbance measured at $560 \mathrm{~nm}$ (Multiskan ${ }^{\mathrm{TM}} \mathrm{EX}$; Thermo Fisher Scientific, Langenselbold, Germany). Cell proliferation was quantified based on the incorporation of bromodeoxyuridine (BrdU Cell Proliferation ELISA; Roche Diagnostics, Mannheim, Germany). For the analysis of cell death, after treatment e.g. under hypoxic conditions, adherent and non-adherent cells were collected, washed in phosphate-buffered saline (PBS), stained with $1 \mu \mathrm{g} / \mathrm{ml}$ propidium iodide (PI) and analyzed by flow cytometry (BD Canto II, Heidelberg, Germany). PI-positive cells were regarded as dead cells. Caspase activity was assessed using the fluorescent substrate DEVD-amc as previously described (31) and a Mithras LB 940 microplate reader (Berthold Technologies, Bad Wildbad, Germany).

ROS analysis. Following treatment e.g. under hypoxic conditions, cells were washed twice with PBS, incubated for $20 \mathrm{~min}$ at $37^{\circ} \mathrm{C}$ in the presence of $10 \mu \mathrm{M} \mathrm{H}_{2}$ DCFDA (Invitrogen, Carlsbad, CA, USA) washed with PBS and analyzed by flow cytometry.

Determination of glucose uptake. Glucose concentrations of cell-free supernatants were measured on a Hitachi 917 analyzer (Roche Diagnostics). Furthermore, cells were incubated for 10 , 75 and $150 \mathrm{~min}$, respectively, in medium supplemented with $100 \mu \mathrm{M} 2-\mathrm{NBDG}$ (Invitrogen) under normoxic or hypoxic conditions. Afterwards, cells were washed twice with PBS, detached, resuspended in PBS containing $1 \mu \mathrm{g} / \mathrm{ml}$ PI and analyzed by flow cytometry at $465 / 540 \mathrm{~nm}$. PI-positive (dead) cells were excluded from the analysis.

Measurement of oxygen consumption. Cells were seeded in glass dishes. After $24 \mathrm{~h}$ medium was changed to pre-incubated treatment medium and the dishes were sealed air-tight. After another $48 \mathrm{~h}$, oxygen concentration in the culture medium was measured in an ABL-80 FLEX Blood Gas Analyzer (Radiometer, Willich, Germany). Oxygen consumption was then normalized to protein concentration (32). Furthermore, oxygen consumption was determined using an XF96 extracellular flux analyzer (Seahorse Bioscience, North Billerica, MA, USA).
Luciferase reporter assay. Using Metafectene Pro, cells were cotransfected with a 3HRE-pTK-luc (23) and, for normalization of transfection efficiency, a pRL-CMV Renilla luciferase construct. Activities of Firefly and Renilla luciferase (33) were analyzed in an Infinite ${ }^{\circledR}$ M200 PRO microplate reader (Tecan, Maennedorf, Switzerland).

SDS-PAGE and immunoblotting. Cells were lysed in a buffer containing $50 \mathrm{mM}$ Tris- $\mathrm{HCl}, 120 \mathrm{mM} \mathrm{NaCl}, 5 \mathrm{mM}$ EDTA, $0.5 \%$ Nonidet P-40, $2 \mu \mathrm{g} / \mathrm{ml}$ aprotinin, $10 \mu \mathrm{g} / \mathrm{ml}$ leupeptin, $100 \mu \mathrm{g} / \mathrm{ml}$ phenylmethylsulfonyl fluoride, $50 \mathrm{mM} \mathrm{NaF}$, $200 \mu \mathrm{M} \mathrm{NaVO}_{5}$ and phosphatase inhibitor cocktails I and II (Sigma-Aldrich) and protein content was quantified using a Bradford assay (Bio-Rad, Hercules, CA, USA). Total protein $(20 \mu \mathrm{g})$ was separated under reducing conditions by sodium dodecyl sulfate polyacrylamide gel electrophoresis (SDS-PAGE) and electroblotted on nitrocellulose (Amersham, Braunschweig, Germany). Membranes were blocked in Trisbuffered saline containing 5\% skim milk and $0.1 \%$ Tween-20 and incubated with the appropriate primary (dilution 1:1,000) and secondary (dilution 1:3,000) antibodies. Immune complexes were detected by enhanced chemiluminescence (Pierce, Rockford, IL, USA). Densitometric analysis was performed using ImageJ according to http://rsb.info.nih.gov/ij/ docs/menus/analyze.html\#gels (34).

Real-time quantitative PCR (RT-qPCR). Extraction of total RNA was performed using TRIzol ${ }^{\mathrm{TM}}$ (Invitrogen) and the RNeasy ${ }^{\mathrm{TM}}$ system (Qiagen), cDNA synthesis using $1.5 \mu \mathrm{g}$ of RNA and SuperScript VILO ${ }^{\mathrm{TM}}$ (Invitrogen). RNA originating from normal human brain was used with institutional review board approval (University Cancer Center Frankfurt). Real-time PCR was carried out in an iQ5 real-time PCR detection system (Bio-Rad, Munich, Germany) with ABsolute ${ }^{\mathrm{TM}}$ Blue qPCR SYBR-Green Fluorescein Mix (Thermo Fisher Scientific, Waltham, MA, USA). Gene expression data were normalized to the internal controls 18S ribosomal RNA (18S rRNA) and succinate dehydrogenase complex, subunit A, flavoprotein variant (SDHA) using the ddCT method and the iQ5 software (Bio-Rad). Primer sequences: 18S rRNA, forward 5'-CGGCTACCACATCC AAGGAA-3' and reverse 5'-GCTGGAATTACCGCGGCT-3'; BIM (35), CITED2 (36), FOXO1 forward 5'-ATACATATGGCC AATCCAGCATG-3' and reverse 5'-CTTCAAGAGTCCAGGC GCAC-3'; FOXO3a forward 5'-GAAGTTCCCCAGCGACT TGG-3' and reverse 5'-CCAACCCATCAGCATCCATG-3'; glucose transporter 1 (GLUT1), forward 5'-GATTGGCTCCT T CTCTGTGG-3' and reverse 5'-TCAAAGGACTTGCCCAG TTT-3'; manganese superoxide dismutase (MnSOD2) forward 5'-AAGGGAGATGTTACAGCCCAGATA-3' and reverse 5'-TCC AGAAAATGCTATGATTGATATGAC-3' (RTPrimerDB ID 2593); SDHA forward 5'-TGGGAACAAGAGGGCAT CTG-3' and reverse 5'- CCACCACTGCATCAAATTCATG-3'; solute carrier family 16 , member 3 (monocarboxylic acid transporter 4) (SLC16A3) (37), TRAIL (35), vascular endothelial growth factor (VEGF), forward 5'-CTACCTCCACCATGCCA AGT-3' and reverse 5'-ATGTTGGACTCCTCAGTGGG-3'.

Immunohistochemistry (IHC). Glioma tissue specimens were derived from the University Cancer Center tumor bank (Goethe University, Frankfurt am Main, Germany) and fixed 

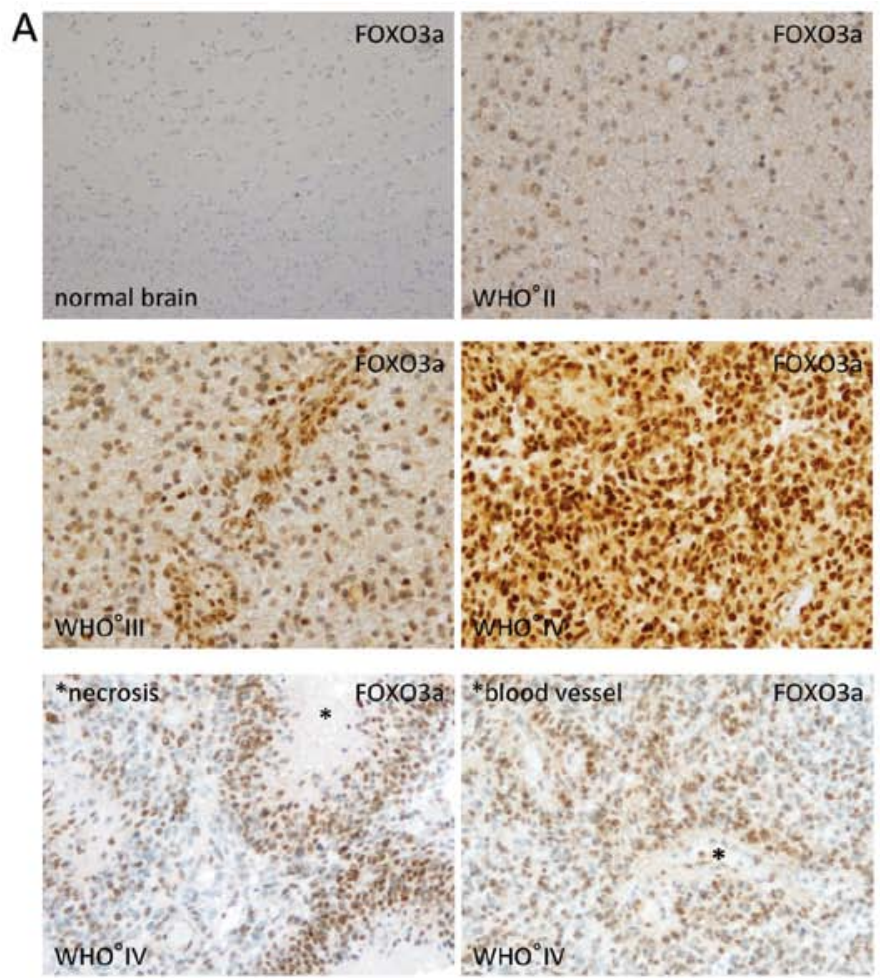
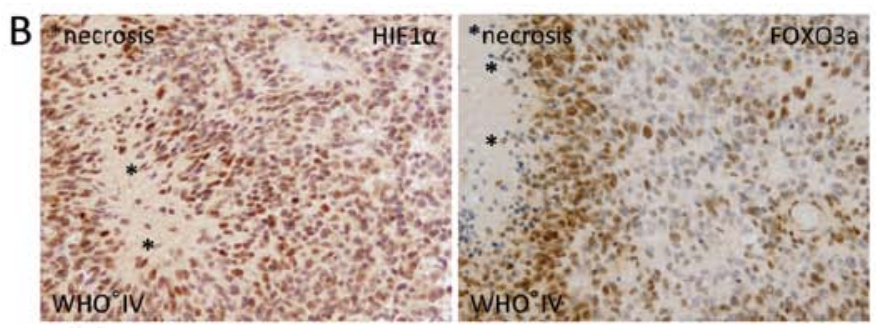

C
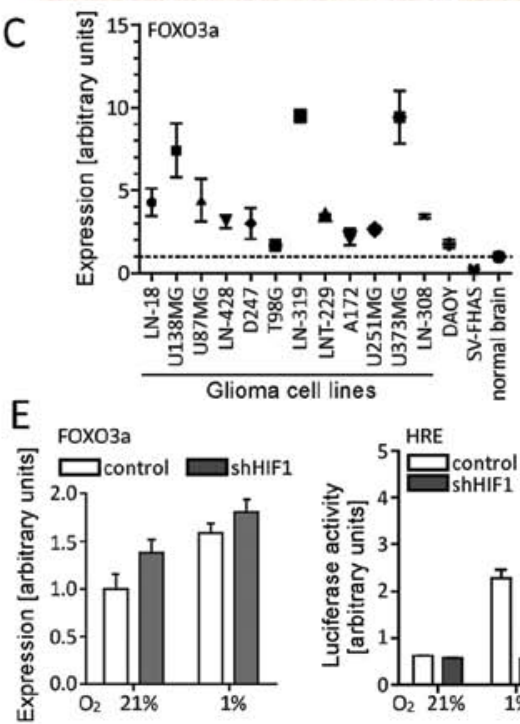

D 2.5 FOXO3a
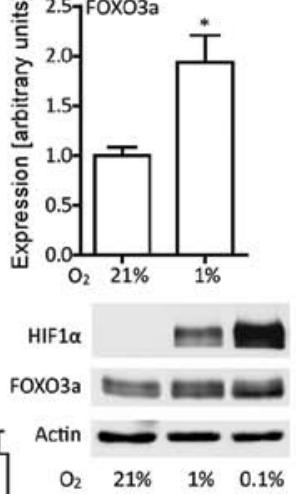

Figure 1. FOXO3a is expressed in human glioma samples, particularly in perinecrotic regions, and induced under hypoxic conditions in a HIF1-independent way. (A) Specimens of normal brain and glioma tissue of different WHO grades were immunohistochemically stained for FOXO3a. (B) Immunohistochemical staining revealed a colocalization of HIF1 $\alpha$ and FOXO3a within the perinecrotic rim in glioblastoma tissue. (C) Expression of FOXO3a in various human glioma cell lines, in a human medulloblastoma cell line (DAOY), in a human fetal astroglial cell line (SV-FHAS) and in human normal brain was analyzed by RT-qPCR (mean \pm SEM). (D) LNT-229 cells were incubated in normoxia or hypoxia for 6 h. FOXO3a expression was assessed by RT-qPCR and western blot analysis (mean \pm SEM; *p<0.05). (E) LNT-229 cells stably expressing shRNA targeting HIF1 (shHIF1) or its Drosophila homolog Sima (control) were subjected to normoxia or hypoxia and FOXO3a expression was analyzed by RT-qPCR (left panel). To verify successful HIF1 silencing, HIF specific transcriptional activity was examined by luciferase reporter assay (3HRE-pTK-luc construct, right panel).

in $4 \%$ paraformaldehyde (formalin). The use of patient material was endorsed by the local ethics committee (Goethe University). Immunohistochemistry for FOXO3a and HIF1 $\alpha$ was performed as previously described (38) using freshly cut $3 \mu \mathrm{m}$ thick slides from formalin-fixed, paraffin-embedded tissue samples on the automated IHC staining system Discovery XT (Roche/Ventana, Tucson, AZ, USA).

Fluorescence microscopy. LNT-229 cells stably expressing FOXO3a-GFP were seeded on glass coverslips coated with poly-L-lysine and allowed to adhere overnight. After treatment, cells were washed with PBS, fixed in $2 \%$ paraformaldehyde, washed twice with PBS, stained with 4',6-diamidino-2-phenylindole (DAPI, $1 \mu \mathrm{g} / \mathrm{ml}$ in PBS) and analyzed by fluorescence microscopy (BZ-8000; Keyence, Osaka, Japan).

Statistical analysis. Experiments were performed at least three times with similar results. Data analysis was carried out with Excel (Microsoft, Seattle, WA, USA). Significance was tested using the two-tailed Student's t-test.

\section{Results}

FOXO3a expression increases with glioma WHO grade. In order to assess expression and localization of FOXO3a in gliomas, we performed immunohistochemistry on tissue samples of a panel of gliomas with different WHO grades. We observed that expression increased with WHO grade and accentuated in perinecrotic and perivascular tumor regions (Fig. 1A). To identify hypoxic areas, we additionally performed immunohistochemical staining of HIF1 $\alpha$. This revealed a similar distribution pattern of FOXO3a and HIF $1 \alpha$ especially in perinecrotic 'pseudopalisading' glioma cells (Fig. 1B) where restricted availability of oxygen and nutrients is expected (39). Subsequently, we compared FOXO3a mRNA and protein expression in different established glioma cell lines and normal brain. All glioma cell lines exhibited elevated FOXO3a expression compared to normal brain (Fig. 1C) (data not shown).

FOXO3a is upregulated under hypoxic conditions in a HIFl-independent manner. To test our immunohistochemical observations, we analyzed FOXO3a expression under hypoxic conditions in vitro. Both mRNA and protein levels increased in LNT-229 glioma cells (Fig. 1D). However, shRNA-mediated silencing of the HIFl $\alpha$ gene did not result in reduced $F O X O 3 a$ levels indicating that HIF1 $\alpha$ was not the primary mediator of elevated FOXO3a expression under hypoxic conditions (Fig. 1E). As HIF2 $\alpha$ may compensate for HIF $1 \alpha$ deficiency, we also analyzed FOXO3a levels in $H I F 2 \alpha$ 
A

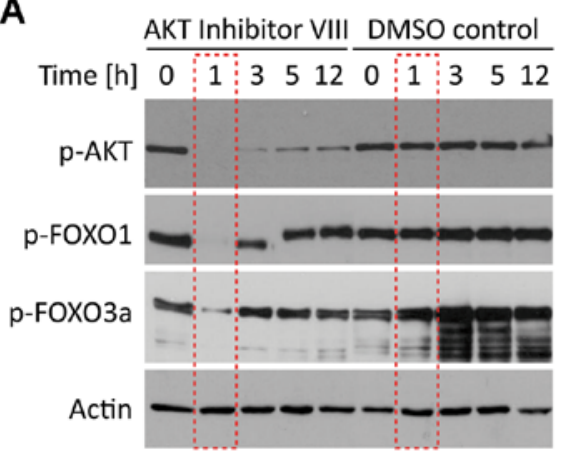

B

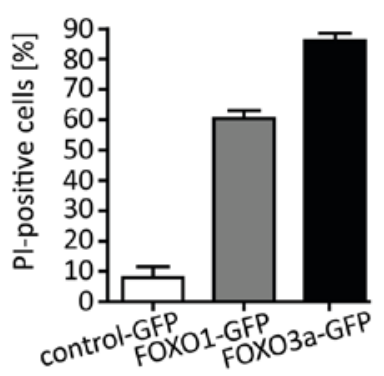

C

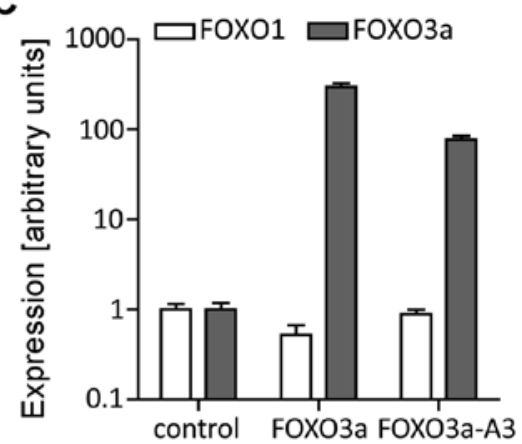

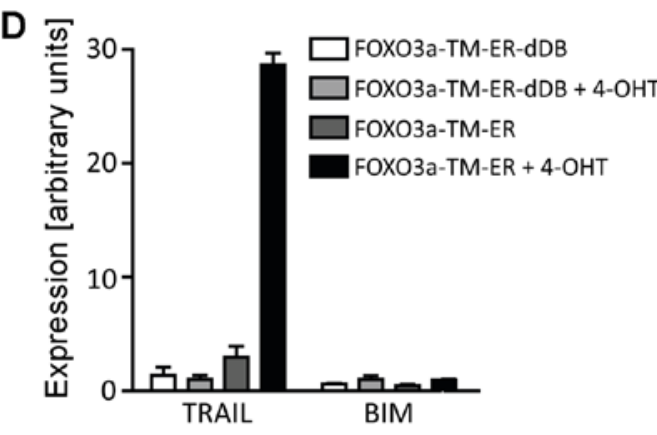
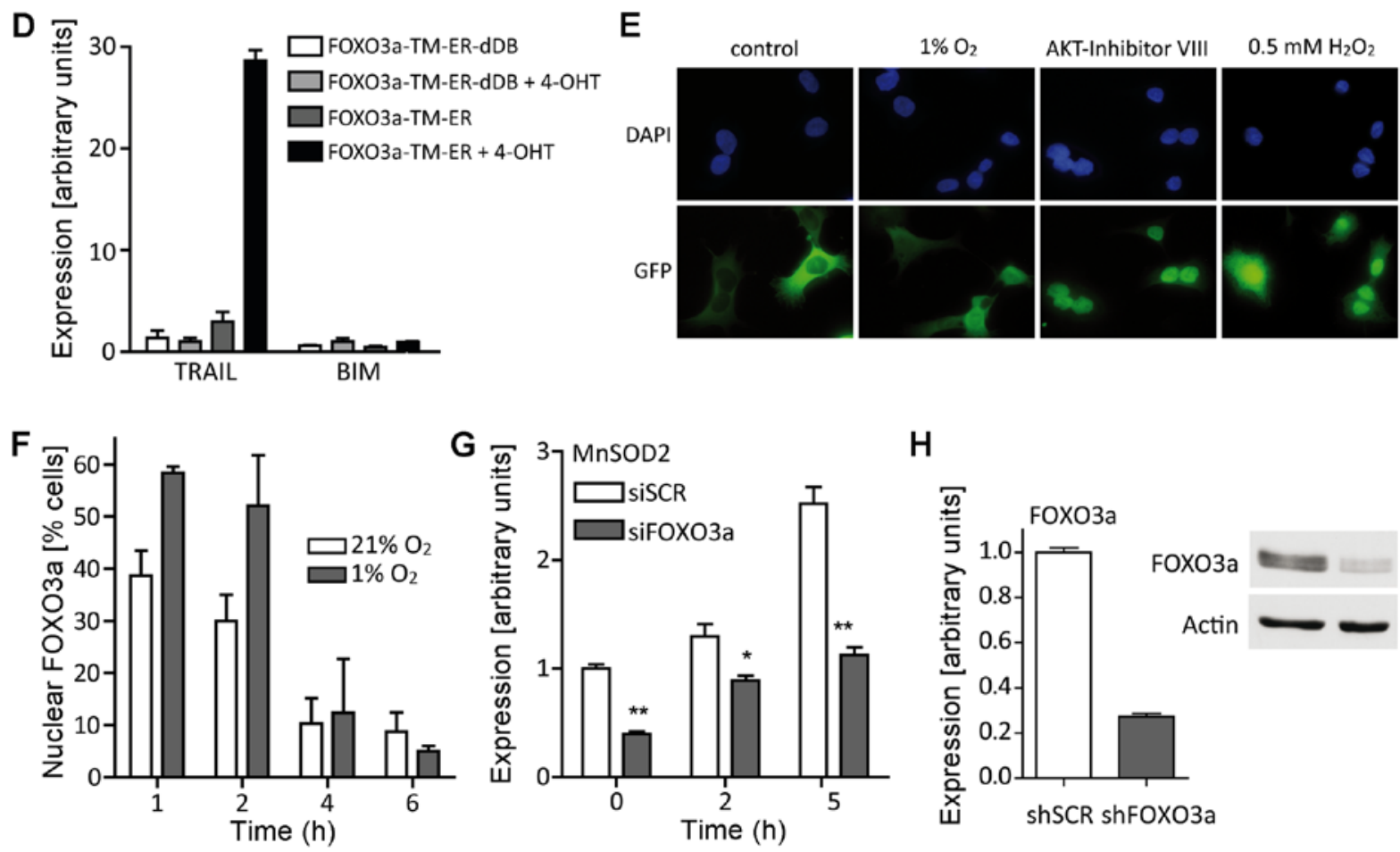

$\mathrm{H}$

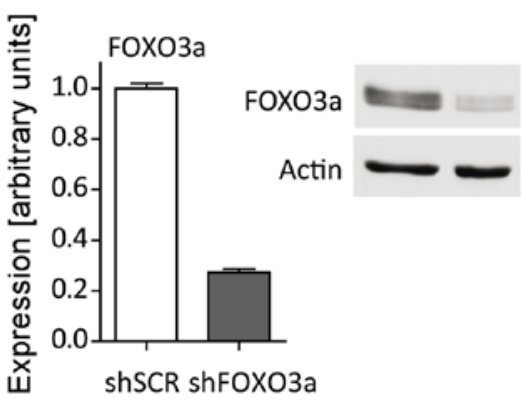

Figure 2. FOXO overexpression provokes cell death and different stressors result in FOXO3a translocation from the cytoplasm to the nucleus. (A) LNT-229 cells were treated with AKT inhibitor VIII (5 $\mu \mathrm{M})$ or DMSO control for the indicated periods of time and whole cell lysates were subjected to SDS-PAGE and immunoblotting against phospho-AKT, phospho-FOXO1 and phospho-FOXO3a. (B) LNT-229 cells were transiently transfected with plasmids encoding FOXO1-GFP, FOXO3a-GFP or, as a control, GFP. After $48 \mathrm{~h}$, cell viability was determined by PI staining and flow cytometry (mean \pm SEM). Equal transfection efficiency was verified by fluorescence microscopy for GFP. (C) Transient overexpression of FOXO3a or constitutive nuclear FOXO3a (FOXO3a-A3) did not increase FOXO1 mRNA levels 24 h post-transfection (mean \pm SEM). (D) LNT-229 cells were transiently transfected with plasmids encoding a 4-hydroxytamoxifen (4-OHT) inducible, constitutive nuclear FOXO3a-TM-construct or the corresponding control FOXO3a-TM-ER-dDB without DNA-binding domain. TRAIL and BIM expression was assessed $24 \mathrm{~h}$ after addition of 4-OHT or DMSO control (mean \pm SEM). (E) LNT-229 cells stably expressing FOXO3a-GFP were serum-starved and exposed to hypoxia, AKT inhibitor VIII or $\mathrm{H}_{2} \mathrm{O}_{2}$. Subcellular FOXO3a localization was examined by fluorescence microscopy. (F) Twenty-four hours after seeding, culture medium was replaced by serum-free medium containing 5 mM glucose. After 1, 2 , 4 and 6 h, LNT-229 cells stably expressing FOXO3a-GFP were fixed, stained with DAPI and analyzed for FOXO3a-GFP localization by fluorescence microscopy (mean \pm SEM). (G) LNT-229 cells were incubated with $0.5 \mathrm{mM} \mathrm{H}_{2} \mathrm{O}_{2}$ in serum-free medium containing $5 \mathrm{mM}$ glucose for $0 \mathrm{~h}$ (control), 2 and $5 \mathrm{~h}$, respectively. MnSOD2 levels were determined by RT-qPCR after treatment with $\mathrm{H}_{2} \mathrm{O}_{2}$ and siRNA-mediated knockdown of FOXO3a (50 nM) or scrambled (SCR) control (mean \pm SEM, ${ }^{*} \mathrm{p}<0.05$ and $\left.{ }^{* *} \mathrm{p}<0.01\right)$. (H) shRNA-mediated FOXO3a knockdown was verified by RT-qPCR and western blot analysis.

knockdown as well as in $H I F l \alpha-H I F 2 \alpha$ double-knockdown LNT-229 cells. Both in normoxia and in hypoxia, depletion of HIF $2 \alpha$ or simultaneous depletion of HIF $1 \alpha$ and HIF $2 \alpha$ did not affect $F O X O 3 a$ expression (data not shown).

FOXO3a overexpression induces cell death in LNT-229 cells. First, we verified that inhibition of PKB activity resulted in dephosphorylation of FOXO1 and FOXO3a in our glioma cell line (Fig. 2A). To monitor changes in FOXO3a subcellular localization, we carried out immunofluorescence studies employing FOXO3a-GFP cells (25). Transient expression of FOXO3a-GFP induced cell death in LNT-229 cells and this cell death was more pronounced than when introducing FOXO1-GFP (Fig. 2B). As both FOXO3a and FOXO1 alone may act pro-apoptotically $(40,41)$, we analyzed $\mathrm{FOXO1}$ expression after transient transfection of $\mathrm{FOXO3a}$ constructs. Enhanced $\mathrm{FOXO3a}$ expression did not affect $\mathrm{FOXO1}$ mRNA levels (Fig. 2C). Using a 4-hydroxytamoxifen (4-OHT) inducible, constitutive nuclear FOXO3a-TM-construct (27) and the corresponding control FOXO3a-TM-ER-dDB without DNA-binding domain, we observed a strong increase in TRAIL expression induced by FOXO3a (Fig. 2D). However, cell death 
occurring upon transfection with constructs encoding FOXO3a and a constitutive nuclear FOXO3a-A3 was inhibitable by Z-VAD-fmk only to a lesser extent whereas Z-VAD-fmk completely reversed TRAIL-induced cell death which served as a positive control (data not shown). Presumably, like TP53, FOXO3a may trigger both apoptosis and autophagy (42) and cell death following $\mathrm{FOXO} 3 \mathrm{a}$ overexpression has frequently been described (41).

LNT-229 cells modulate the subcellular localization of FOXO3a in response to environmental stress and pharmacological inhibition of PKB. Counteracted by phosphatase and tensin homolog (PTEN), insulin and growth factor signaling activates PKB that in turn phosphorylates FOXO3a at three conserved residues and thereby causes its cytoplasmic localization (5,43-45). To study changes in the subcellular localization of FOXO3a, we generated LNT-229-cells stably expressing FOXO3a-GFP by repeated selection and fluorescence-activated cell sorting (FACS). Using these cells, we observed FOXO3a shifting to the nucleus after implementation of different stressors: serum deprivation, hypoxia and hydrogen peroxide $\left(\mathrm{H}_{2} \mathrm{O}_{2}\right)$ (Fig. 2E). Extent and duration of this shift varied depending on the kind of stress. Pharmacological blockade of PKB via AKT inhibitor VIII caused an immediate and durable translocation to the nucleus that could partially be reverted by addition of $10 \%$ FCS to the medium (data not shown). Addition of $0.5 \mathrm{mM} \mathrm{H}_{2} \mathrm{O}_{2}$ forced FOXO3a to permanently stay in the nucleus even in the presence of FCS. Nuclear shifting of FOXO3a after serum starvation was strongly enhanced by hypoxia and always a temporary event of short duration $(<4$ h) (Fig. 2F).

FOXO3a gene silencing increases intracellular ROS levels and boosts cell death associated with oxidative stress. ROS are byproducts of aerobic metabolism and involved in diverse cellular functions. On the one hand and at 'lower levels', they support cell proliferation through the activation of growth-related signaling pathways, on the other hand and at 'higher levels', they promote apoptosis. To determine whether FOXO3a regulation contributes to the resistance of malignant glioma cells under conditions of low glucose, low oxygen and high ROS levels, we used four different siRNA sequences targeting $\mathrm{FOXO3a}$ and yielding comparable results. MnSOD2, one of the main antioxidant enzymes and a FOXO3a target gene (46), was upregulated following stimulation with $\mathrm{H}_{2} \mathrm{O}_{2}$. Transient siRNA-mediated suppression of FOXO3a significantly reduced $M n S O D 2$ expression (Fig. 2G). LNT-229-shFOXO3a cells (Fig. 2H) were employed to determine intracellular ROS by flow cytometric analysis of the ROS-sensitive dye dichlorodihydrofluorescein diacetate $\left(\mathrm{H}_{2} \mathrm{DCFDA}\right)$. An increase in intracellular ROS was observed after administration of 0.5-1 $\mathrm{mM} \mathrm{H}_{2} \mathrm{O}_{2}$ in LNT-229-shFOXO3a cells compared to the control cells (Fig. 3A). Loss of FOXO3a not only affected the intracellular ROS homeostasis but also elevated cell death rates after addition of $\mathrm{H}_{2} \mathrm{O}_{2}$. Addition of $10 \%$ FCS to the cell culture medium increased cell death in both LNT-229-shFOXO3a and control cells. Presumably, more ROS were generated by accelerated metabolic processes in the presence of serum, exceeding the detoxification capacity of both cell lines. However, also in this setup, control cells displayed better survival rates than LNT-229-shFOXO3a cells (Fig. 3B). LNT-229-shFOXO3a cells accumulated more intracellular ROS than their control cells, and this was even more pronounced under hypoxia. Severe hypoxia amplified ROS production in both cell lines, again more in LNT-229-shFOXO3a than in control cells (Fig. 3C). Addition of serum also boosted ROS production (data not shown).

FOXO3a promotes cell death in hypoxia in a caspase-independent way. To simulate conditions of the 'perinecrotic niche', we subjected LNT-229 cells to serum-free medium supplemented with $2 \mathrm{mM}$ glucose and normoxia $\left(21 \% \mathrm{O}_{2}\right)$, hypoxia $\left(1 \% \mathrm{O}_{2}\right)$ or severe hypoxia $\left(0.1 \% \mathrm{O}_{2}\right)$. Interestingly, FOXO3a gene suppression conferred robust protection from cell death occurring under starvation conditions (Fig. 3D). Experiments with three different siRNAs targeting $\mathrm{FOXO} 3 a$ revealed the same phenotype (data not shown). Additionally, we employed an adenoviral dominant-negative FOXO3a construct (AdFOXO3aDN) and its control (PADEG) (24). This approach also confirmed the protective effect of FOXO3a inhibition under starvation conditions (Fig. 3E). We measured caspase-3 activity and found neither caspase-3 activation in hypoxia nor a difference between LNT-229-shFOXO3a and control cells. Therefore, in this in vitro paradigm, cell death under hypoxic conditions was non-apoptotic (47) and not affected by a pro-apoptotic function of FOXO3a (Fig. 3F).

FOXO3a gene silencing saves glucose but does not alter cell proliferation. To figure out the processes leading to cell death under starvation conditions, we determined glucose concentrations in culture supernatants of LNT-229-shFOXO3a and control cells. Glucose consumption generally increased in hypoxia and decreased in LNT-229-shFOXO3a cells (Fig. 4A). Similar effects were observed in AdFOXO3aDN cells (Fig. 4B). This difference was not due to a lower proliferation rate of LNT-229-shFOXO3a cells, as assessed by BrdU-incorporation assays (Fig. 4C) and crystal violet staining (Fig. 4D). We also analyzed the cells' glucose flux using the fluorescent D-glucose analog 2-NBDG (48) and flow cytometry. Again, LNT-229-shFOXO3a cells took up less 2-NBDG than the corresponding control cells both in normoxia and in hypoxia (Fig. 4E).

FOXO3a knockdown attenuates oxygen consumption. To investigate whether glioma cells compensate their reduced glucose uptake by enhanced oxidative phosphorylation, we determined oxygen consumption by ABL-80 FLEX blood gas analyzer. Conversely, FOXO3a knockdown resulted in a decrease in oxygen consumption (Fig. 4F). These results were confirmed by experiments conducted with the XF96 extracellular flux analyzer (data not shown).

FOXO3a inhibition amplifies HIFla transcriptional activity in hypoxia. Analysis of primary tumor tissue revealed a perinecrotic expression of FOXO3a matching the regions with higher levels of HIF1 $\alpha$ (Fig. 1B). We therefore aimed to explore potential interactions between FOXO3a and HIF1 $\alpha$. HIF-specific transcriptional activity, examined by luciferase reporter assay (3HRE-pTK-luc construct), increased under hypoxic conditions. FOXO3a knockdown augmented this effect on HRE reporter gene activity (Fig. 5A). To confirm an inhibitory effect of FOXO3a on HIF1 $\alpha$, we transiently 

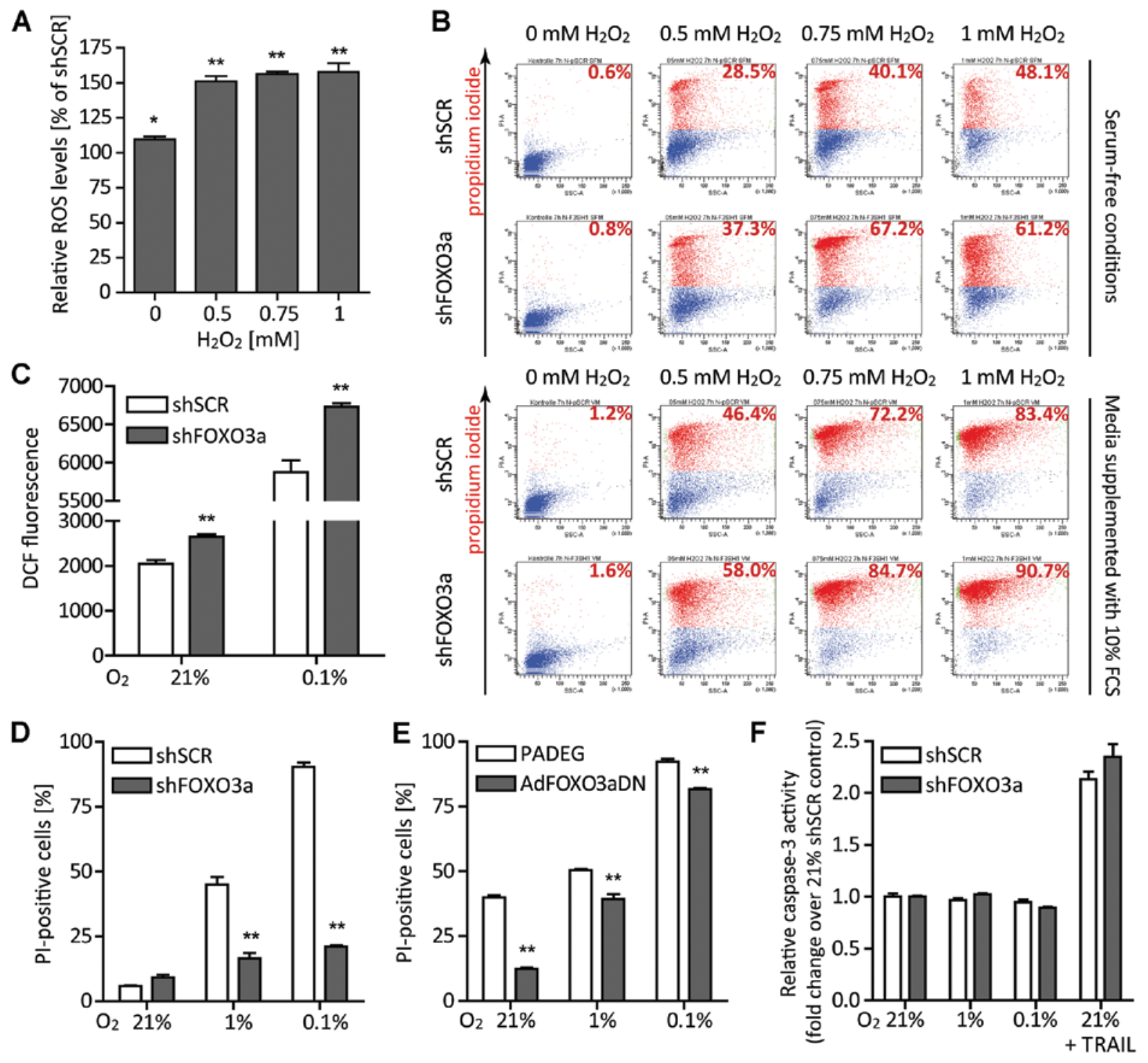

Figure 3. FОХОЗ $a$ knockdown elevates ROS levels, enhances cell death linked to oxidative stress and confers protection from non-apoptotic cell death under starvation conditions. (A) $\mathrm{H}_{2} \mathrm{O}_{2}$ was added to the medium to give final concentrations of $0 \mathrm{mM}$ (control), $0.5,0.75$ and $1 \mathrm{mM}$. After a $6 \mathrm{~h}$ incubation period, DCF fluorescence was determined by flow cytometry. Results are expressed as median fluorescence intensities of LNT-229-shFOXO3a cells relative to the corresponding LNT-229-shSCR (control) cells (mean \pm SEM, ${ }^{*}$ p $<0.05$ and ${ }^{* *}$ p $<0.01$ ). (B) In the absence (upper panel) or presence (lower panel) of $10 \%$ FCS in

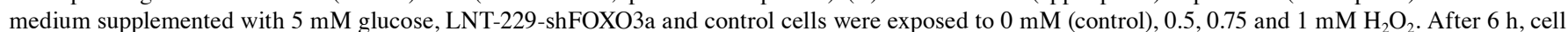
viability was assessed by PI staining and flow cytometry. Results from one representative experiment are depicted. Numbers in each upper right corner denote percentages of PI-positive (dead) cells. (C) For 6 h, LNT-229-shFOXO3a and LNT-229-shSCR cells were cultured under normoxic or hypoxic conditions in serum-free medium containing $5 \mathrm{mM}$ glucose. Thereafter, intracellular ROS generation was estimated using $\mathrm{H}_{2} \mathrm{DCFDA}$ and flow cytometry. Data are displayed as median fluorescence intensities and mean plus SEM of three experiments, ${ }^{* *} \mathrm{p}<0.01$. (D) LNT-229-shFOXO3a cells and their controls LNT-229-shSCR were cultured in serum-free medium supplemented with $2 \mathrm{mM}$ glucose. Following an incubation period of $24 \mathrm{~h}$ under normoxic or hypoxic conditions, cell viability was determined by PI staining and flow cytometry. Data are presented as mean percentages of PI-positive cells and SEM $(*$ p $<0.01)$. (E) The same experiment was performed with LNT-229 cells adenovirally transduced with a dominant-negative FOXO3a and its corresponding control. (F) Again applying the same experimental design, we found that neither hypoxia (combined with serum and glucose starvation) nor FOXO3a knockdown altered DEVD-amc-cleaving caspase activity. Cells treated with TRAIL served as positive controls. Results are displayed as fold-change over the $21 \%$ shSCR control plus SEM.

overexpressed a constitutive nuclear FOXO3a-A3 where all three PKB phosphorylation sites were mutated to alanine (49). This resulted in a marked reduction of HRE reporter gene activity (Fig. 5B). Additionally, we analyzed the expression of several well-known HIF1 target genes using RT-qPCR (50). The expression of vascular endothelial growth factor (VEGF) and the monocarboxylate transporter solute carrier family 16 member 3 (SLC16A3) increased under hypoxic conditions and this was further enhanced by FOXO3a knockdown, suggesting that FOXO3a inhibited HIF1 transcriptional activity in LNT-229 glioma cells (Fig. 5C). To study whether the protective effect of $\mathrm{FOXO} a$ knockdown on survival under hypoxia was mediated by HIF1 $\alpha$, we applied siRNA targeting FOXO3a under starvation conditions in LNT-229 cells stably transfected with an shRNA targeting HIFla or its control (Sima), respectively (30). Loss of HIF1 $\alpha$ abolished the protection conferred by FOXO3a knockdown in hypoxia (Fig. 5D).

GLUT1 expression is reduced in the absence of FOXO3a. The expression of GLUT1, another long-known HIF1 target gene, decreased following $\mathrm{FOXO} a$ knockdown. Though induced under hypoxic conditions (51) both in LNT-229-shFOXO3a and 
A

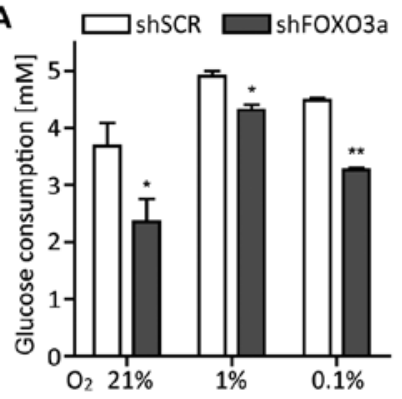

B

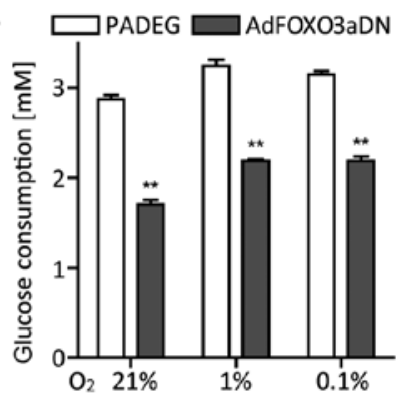

C

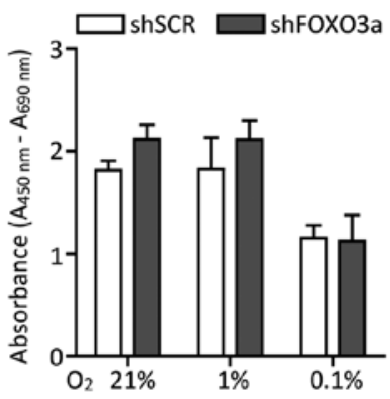

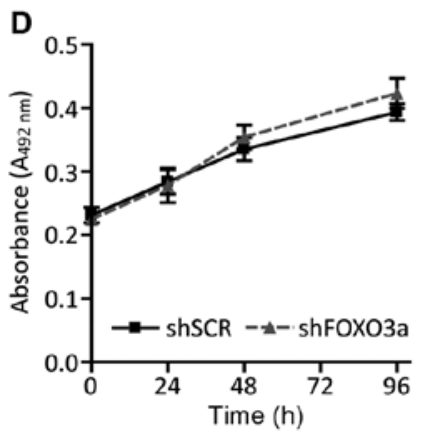
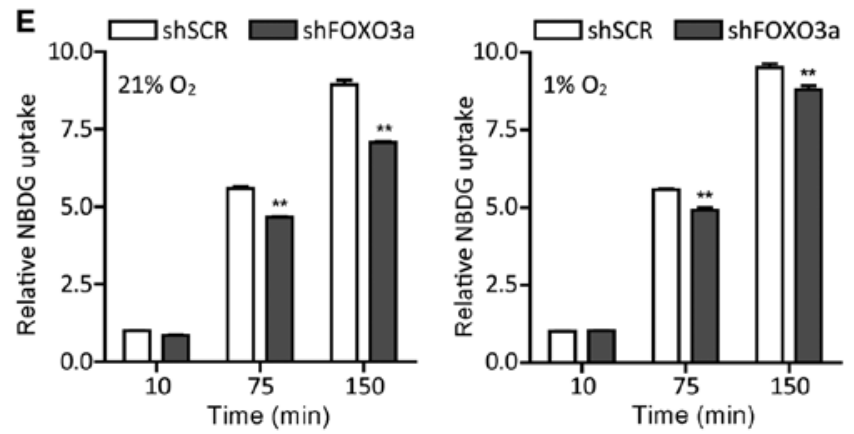

$\mathbf{F}$

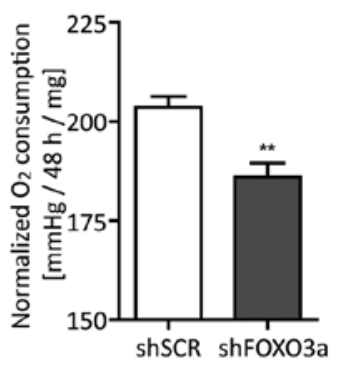

Figure 4. Attenuation of FOXO3a lowers glucose and oxygen consumption whilst maintaining proliferative capacity. (A) Twenty-four hours after seeding in medium supplemented with 10\% FCS and $25 \mathrm{mM}$ glucose, LNT-229-shFOXO3a and control cells were grown in serum-free medium containing $5 \mathrm{mM}$ glucose for another $24 \mathrm{~h}$. Then, residual glucose in supernatants was measured (mean $\pm \mathrm{SEM},{ }^{*} \mathrm{p}<0.05$ and ${ }^{* *} \mathrm{p}<0.01$ ). (B) We also observed this glucose-saving phenotype when using the adenoviral dominant-negative FOXO3a construct (mean \pm SEM, ${ }^{*} p<0.05$ and $\left.{ }^{* *} \mathrm{p}<0.01\right)$. (C) BrdU incorporation decreased in severe hypoxia, but did not differ significantly between the two cell lines (mean \pm SEM). (D) Glioma cells were grown in medium containing $5 \mathrm{mM}$ glucose and normoxic cell density was assessed by crystal violet staining at day 1,2,3 and 4 (mean \pm SEM). (E) LNT-229-shFOXO3a and control cells were cultured under normoxic or hypoxic conditions for $24 \mathrm{~h}$. Hereafter, pre-incubated medium containing 2-NBDG, a fluorescent derivative of D-glucose, was added. After 10, 75 and $150 \mathrm{~min}$, cells were washed, stained with PI and analyzed by flow cytometry. Data are presented as median fluorescence intensities relative to the 10 min value of LNT-229-shSCR (control) cells and SEM, ${ }^{* *} \mathrm{p}<0.01$. (F) Oxygen consumption was calculated by subtracting oxygen concentration after a $48 \mathrm{~h}$ incubation period from initial oxygen concentration and to exclude any potential differences in proliferation, normalized to protein content (mean $\pm \mathrm{SEM}$, $\left.{ }^{* *} \mathrm{p}<0.01\right)$.

control cells, GLUT1 expression of control cells always exceeded that of cells lacking FOXO3a (Fig. 5E). To verify the RT-qPCR data, we analyzed surface GLUT1 levels by flow cytometry. This technique also revealed higher GLUT1 amounts in hypoxia and lower amounts in LNT-229-shFOXO3a cells (Fig. 5F). The expression of HIF1 target genes was thus differentially affected by $F O X O 3 a$ knockdown in our glioma cell line.

The effect of FOXO3a knockdown is not mediated by CITED2. As reported by Bakker et al, FOXO3a is induced in hypoxia and activates the transcription of CITED2 (36). CITED2 in turn impairs HIF1 activity by competing with HIF1 for binding to the transcriptional coactivator CBP/p300 (52). We hypothesized that CITED2 also could be the mediator of the phenotype observed in our cell line. Induction of CITED2 in hypoxia was suppressed by FOXO3a knockdown (Fig. 6A). Nevertheless, a CITED2 knockdown did not display the protective phenotype of the FOXO3a knockdown under hypoxic conditions (Fig. 6B). Regarding the glucose consumption of cells transiently transfected with siRNA, a CITED2 knockdown increased glucose consumption instead of decreasing it (Fig. 6C). Obviously, CITED2 was not the missing link between FOXO3a and HIF1 and did not account for either the diminished GLUT1 expression or finally the protection under starvation conditions.

FOXO3a decreases TP53 transcriptional activity. As GLUT1 expression is known to be downregulated by TP53 (53) and
FOXO3a can promote the translocation of TP53 to the cytoplasm (54), we reflected on TP53 potentially being involved in the reduced glucose consumption associated with $\mathrm{FOXO3a}$ knockdown. Indeed, also in our glioma cell line, FOXO3a knockdown increased TP53 transcriptional activity (Fig. 6D) as well as its phosphorylation at serine 15 (Fig. 6E) that is considered necessary for TP53 function (55). Considering our previous studies on the role of TP53 in LNT-229 glioma cells (32), the interplay of FOXO3a and TP53 may partially explain the phenotype observed under starvation conditions because antagonizing TP53 enhances cell death when availability of glucose and oxygen is restricted. Elevated TP53 activity in LNT-229-shFOXO3a cells could therefore improve cell survival in unfavorable environments.

\section{Discussion}

Members of the FOXO family of transcription factors are key players in the regulation of cell-fate decisions, such as cell death, proliferation and metabolism. They are negatively regulated by the serine/threonine kinase PKB that in turn is often hyperactivated in glioblastoma, e.g., due to mutation and inactivation of PTEN (56) and upstream receptor tyrosine kinase signaling (12).

Our immunohistochemical studies on human glioma tissue sections illustrated that $\mathrm{FOXO} 3 \mathrm{a}$ expression increased with WHO grade and was accentuated in perinecrotic tumor regions. This finding disagrees with data published by Shi et al 

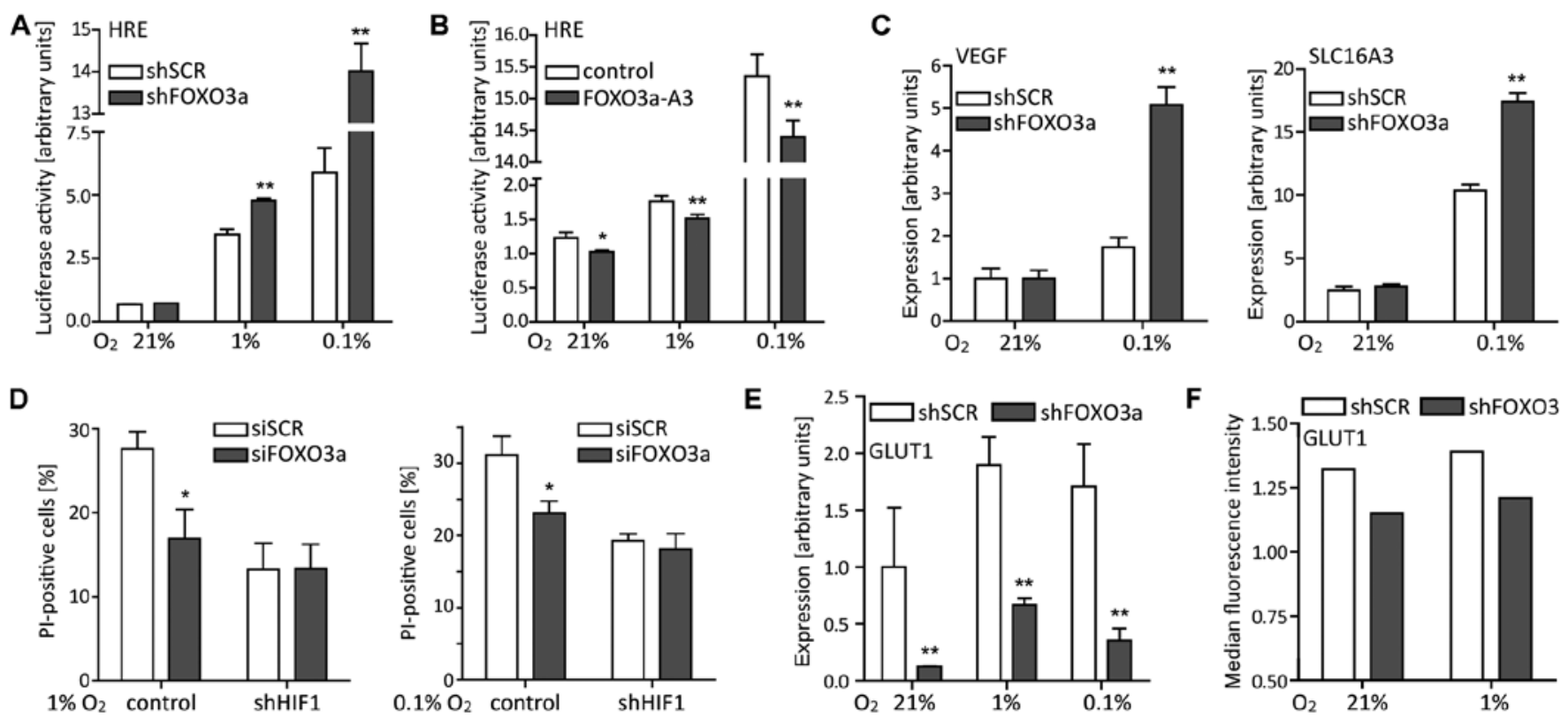

Figure 5. FOXO3a differentially affects HRE-dependent transcriptional activity and target gene expression. (A) LNT-229-shFOXO3a and control cells were cultured in serum-free medium containing $5 \mathrm{mM}$ glucose and under different oxygen conditions. After $24 \mathrm{~h}$, HIF-specific transcriptional activity was examined by luciferase reporter assay (3HRE-pTK-luc construct, mean \pm SEM, ${ }^{* *} \mathrm{p}<0.01$ ). (B) Inversely, transient overexpression of constitutive nuclear FOXO3a-A3 reduced HRE-dependent transcriptional activity (mean \pm SEM, ${ }^{*}$ p $<0.05$ and ${ }^{* *}$ p $<0.01$ ). (C) LNT-229-shFOXO3a and LNT-229-shSCR cells were grown in normoxia or hypoxia for $24 \mathrm{~h}$. Expression of $V E G F$ and $S L C 16 A 3$ was analyzed by RT-qPCR (mean \pm SEM, ${ }^{* *}$ p $<0.01$ ). (D) In LNT-229 cells stably transfected with a shRNA construct targeting HIFla (shHIF1), additional FOXO3a knockdown failed to protect cells under starvation conditions. Subsequent to 24 h of serum, glucose and oxygen restriction (see Fig. 3), cell viability was determined by PI staining and flow cytometry (mean \pm SEM, ${ }^{*}$ p $<0.05$ ). (E) FOXO3a knockdown decreased GLUT1 expression (for the experimental setup see above, mean \pm SEM, ${ }^{* *}$ p $<0.01$ ). (F) Following a 24 h incubation in normoxia or hypoxia, cell-surface levels of GLUT1 were determined by flow cytometry. PI-positive (dead) cells were excluded from the analysis. Results from one representative experiment are shown.
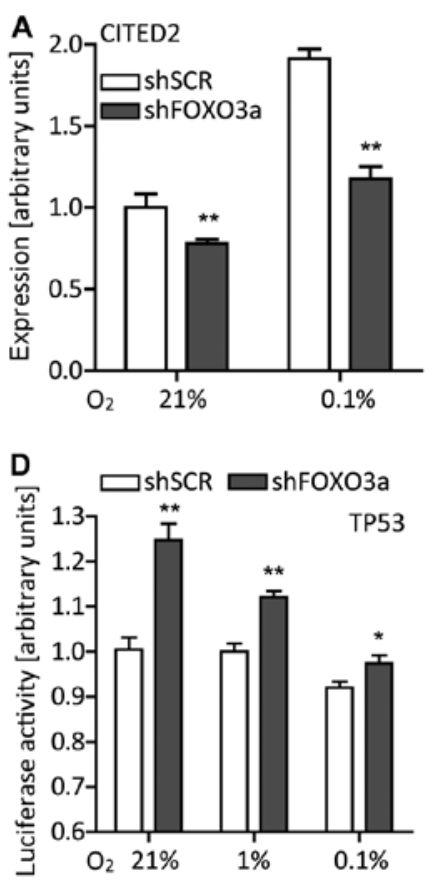
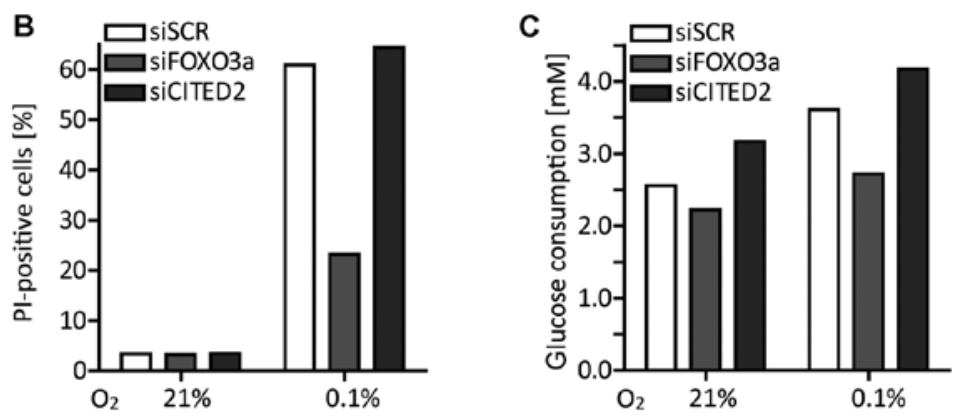

E

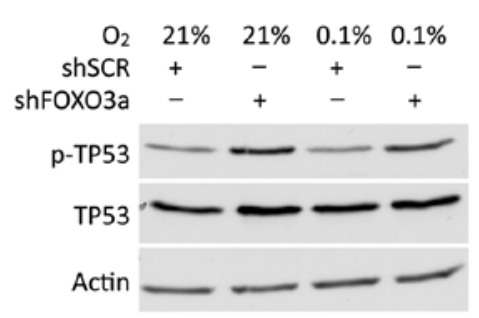

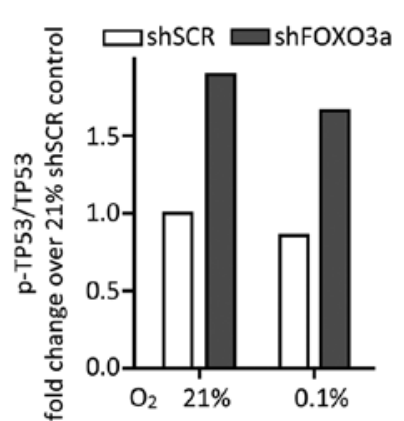

Figure 6. The effects of the FOXO3a knockdown cannot be explained by the action of CITED2, but at least partially by an interaction with TP53. (A) Under normoxic or hypoxic conditions, LNT-229-shFOXO3a and control cells were grown in serum-free medium supplemented with 5 mM glucose. After 24 h, CITED2 expression was assessed by RT-qPCR (mean \pm SEM, **p<0.01). (B) LNT-229 cells transiently transfected with siRNA targeting CITED2 were exposed to normoxia or hypoxia in serum-free medium containing $2 \mathrm{mM}$ glucose. After $24 \mathrm{~h}$, cell death was evaluated by PI staining and flow cytometry. Percentages of PI-positive (dead) cells from one representative experiment are shown. (C) Cells were grown in serum-free medium supplemented with $5 \mathrm{mM}$ glucose and in normoxia or hypoxia. After $24 \mathrm{~h}$, remaining glucose concentrations were measured and glucose consumption was calculated. Results from one representative experiment are shown. (D) LNT-229-shFOXO3a and control cells were cultured in serum-free medium containing 5 mM glucose and under different oxygen conditions. After $24 \mathrm{~h}$, TP53-mediated reporter gene expression was examined (mean \pm SEM, ${ }^{*}$ p $<0.05$ and ${ }^{* *}$ p $\left.<0.01\right)$. (E) In parallel, cell lysates were analyzed for phosphorylated TP53 at serine 15 (p-TP53), total TP53 and, as a loading control, actin. Results of densitometric analysis are expressed as p-TP53 relative to total TP53 and fold-change over the $21 \% \mathrm{O}_{2}$ condition of LNT-229-shSCR control cells. 

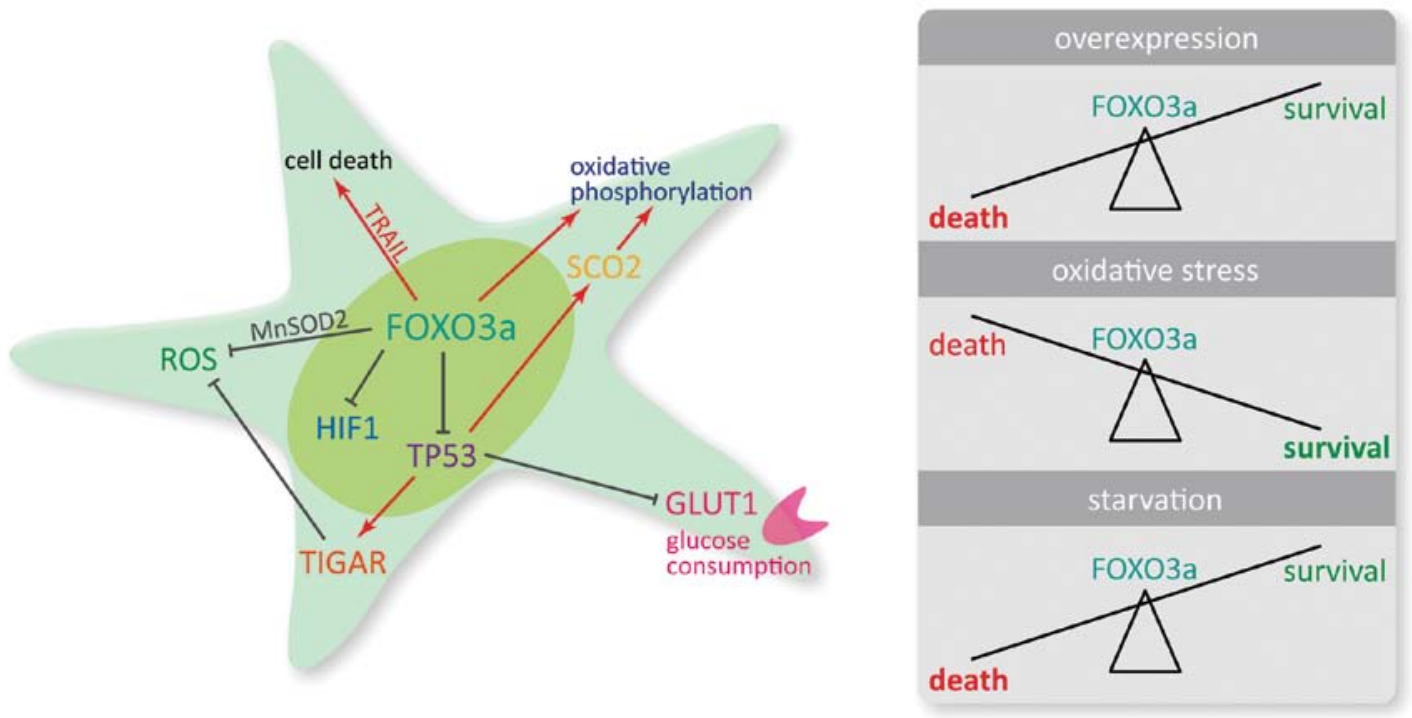

Figure 7. Illustration of FOXO3a-dependent metabolic alterations and their impact on cell viability in different environmental contexts. For details, please see Results and Discussion sections.

suggesting lower FOXO3a levels in grade IV tumors (57). FOXO expression in areas of nutrient deficiency may be comprehensible as a mechanism of survival in nutrient-poor conditions when recalling the FOXO ortholog DAF-16 in Caenorhabditis elegans and its facilitation of developmental arrest at the dauer larval stage supporting survival until environmental conditions improve (58). We analyzed 12 cell lines derived from high grade gliomas and all of them were found to express $\mathrm{FOXO3a}$ to a higher extent than normal brain. LNT-229 cells, used for our further experiments and expressing moderate levels of FOXO3a, were capable of modulating its expression, its phosphorylation and its subcellular location and of regulating the expression of its target genes. Hence, the FOXO3a system was preserved and functional in our glioma cell line.

In the presence of enough glucose, a knockdown of $\mathrm{FOXO} 3 \mathrm{a}$ was detrimental to LNT-229 cells exposed to oxidative stress: FOXO3a-dependent expression of MnSOD decreased, intracellular ROS accumulated and cell death increased. Similarly to our results, Bakker et al (36) and Jensen et al (21) observed an activation of FOXO3a in hypoxia which promoted cell survival. However, in our glioma cell line, upregulation of FOXO3a under hypoxic conditions was not directly associated with HIF1 transcriptional activity.

In the absence of sufficient glucose, a knockdown of FOXO3a turned out to be advantageous for glioma cell survival by reducing the cells' glucose and oxygen consumption. By contrast, in neural stem/progenitor cells, FOXO3a knockout led to increased respiration (59), and, in an immortalized retinal pigment epithelial cell line, FOXO3a activation reduced oxygen consumption rates (60). As metabolism is known to be fine-tuned by numerous factors, those differences may be ascribed to different experimental conditions or cell-type specific characteristics.

Consistent with our observations, Emerling et al described an increase in HIF1 transcriptional activity following FOXO inactivation and the formation of a complex between FOXO3a, HIF1 and p300 under hypoxic conditions resulting in a suppres- sion of HIF1 target genes (61). In our study, the impact of a FOXO3a knockdown on GLUT1 was diametrically opposed to that on other established HIF1 target genes. The downregulation of GLUT1 and the diminished glucose consumption could be attributed to a strengthened activity of TP53 upon FOXO3a knockdown. In previous studies, we observed that TP53 suppressed glycolysis and induced cytochrome $c$ oxidase assembly protein ( $\mathrm{SCO} 2$ ) which in turn promoted oxidative phosphorylation, reduced ROS levels and thereby facilitated cell viability under starvation conditions (32). TP53-induced glycolysis and apoptosis regulator (TIGAR) activated the pentose phosphate pathway (PPP), promoting NADPH production and protection against ROS (62). TP53 and FOXO3a interrelate with each other in various ways: Firstly, they share several target genes, e.g. p53 upregulated modulator of apoptosis (PUMA), cyclin-dependent kinase inhibitor 1A $(C D K N 1 A)$ and growth arrest and DNA damage-inducible 45 (GADD45) (63). Secondly, TP53 may promote FOXO3a expression $(64,65)$, but impair FOXO3a function via serumand glucocorticoid-inducible kinase 1 (SGK1) (66) as well as following oxidative stress (67) and, via E3 ubiquitin protein ligase (MDM2), endorse its degradation (68). Thirdly, FOXO3a can bind to TP53 (69) and compromise its transcriptional activity (54). This obviously complex regulatory system including feedback loops allows to coordinate the cell's response to environmental stress. Known to interact with numerous transcription factors, $\mathrm{CBP} / \mathrm{p} 300$ may be the missing link between FOXO3a, HIF1 and TP53 (70). As its availability in the cell is limited, multiple proteins compete with each other for binding to $\mathrm{CBP} / \mathrm{p} 300$ and thus modulate their action. Nevertheless, we did not further address this topic and so it remains speculative.

In conclusion, our results indicate three defined effects of FOXO3a signaling depending on environmental conditions. Firstly, overexpression of FOXO3a results in enhanced cell death that is accompanied by increased expression of TRAIL. Secondly, in the absence of other starvation signals, physiological levels of FOXO3a prevent glioma cells from cell death 
following oxidative stress, presumably by inducing $\mathrm{MnSOD}$ expression. Thirdly, in situations of reduced oxygen and limited glucose supply, FOXO3a sensitizes glioma cells to death by increasing glucose and oxygen consumption. This phenotype may be attributable to interactions with HIF1 $\alpha$ and TP53 resulting in differential regulation of target genes, in particular of GLUT1, which is a key gene regulating uptake of glucose in cancer cells (71). The versatile role of FOXO3a in the maintenance of metabolic homeostasis should therefore be taken into consideration when targeting upstream regulators of FOXO3a function, since they may profoundly alter the susceptibility of glioma cells towards cell death. This could be of particular importance in cells that inhabit the perinecrotic niche and may be exposed to transient and recurrent episodes of hypoxia which have been shown to promote tumor evolution and therapy resistance (18,72-74). Fig. 7 shows our findings on the impact of FOXO3a on metabolic key parameters and cell viability.

\section{Acknowledgements}

The Dr. Senckenberg Institute of Neurooncology was supported by the Hertie foundation and the Dr. Senckenberg foundation. JPS is 'Hertie Professor for Neurooncology'.

\section{References}

1. Coomans de Brachène $\mathrm{A}$ and Demoulin JB: FOXO transcription factors in cancer development and therapy. Cell Mol Life Sci 73: 1159-1172, 2016.

2. Eijkelenboom A and Burgering BMT: FOXOs: Signalling integrators for homeostasis maintenance. Nat Rev Mol Cell Biol 14 83-97, 2013.

3. Charitou P, Rodriguez-Colman M, Gerrits J, van Triest M, Groot Koerkamp M, Hornsveld M, Holstege F, Verhoeven-Duif NM and Burgering BM: FOXOs support the metabolic requirements of normal and tumor cells by promoting IDH1 expression. EMBO Rep 16: 456-466, 2015.

4. van der Vos KE and Coffer PJ: The extending network of FOXO transcriptional target genes. Antioxid Redox Signal 14: 579-592, 2011.

5. Brunet A, Bonni A, Zigmond MJ, Lin MZ, Juo P, Hu LS, Anderson MJ, Arden KC, Blenis J and Greenberg ME: Akt promotes cell survival by phosphorylating and inhibiting a Forkhead transcription factor. Cell 96: 857-868, 1999.

6. Ho KK, Myatt SS and Lam EW: Many forks in the path: Cycling with FoxO. Oncogene 27: 2300-2311, 2008.

7. Naka K, Hoshii T, Muraguchi T, Tadokoro Y, Ooshio T, Kondo Y, Nakao S, Motoyama N and Hirao A: TGF-beta-FOXO signalling maintains leukaemia-initiating cells in chronic myeloid leukaemia. Nature 463: 676-680, 2010.

8. Tenbaum SP, Ordóñez-Morán P, Puig I, Chicote I, Arqués O, Landolfi S, Fernández Y, Herance JR, Gispert JD, Mendizabal L, et al: $\beta$-catenin confers resistance to PI3K and AKT inhibitors and subverts FOXO3a to promote metastasis in colon cancer. Nat Med 18: 892-901, 2012.

9. Calnan DR and Brunet A: The FoxO code. Oncogene 27: 2276-2288, 2008.

10. van der Horst A and Burgering BM: Stressing the role of FoxO proteins in lifespan and disease. Nat Rev Mol Cell Biol 8: 440-450, 2007

11. Van Der Heide LP, Hoekman MF and Smidt MP: The ins and outs of FoxO shuttling: Mechanisms of FoxO translocation and transcriptional regulation. Biochem J 380: 297-309, 2004.

12. Cancer Genome Atlas Research Network: Comprehensive genomic characterization defines human glioblastoma genes and core pathways. Nature 455: 1061-1068, 2008.

13. Sunayama J, Sato A, Matsuda K, Tachibana K, Watanabe E, Seino S, Suzuki K, Narita Y, Shibui S, Sakurada K, et al: FoxO3a functions as a key integrator of cellular signals that control glioblastoma stem-like cell differentiation and tumorigenicity. Stem Cells 29: 1327-1337, 2011.
14. Lau CJ, Koty Z and Nalbantoglu J: Differential response of glioma cells to FOXO1-directed therapy. Cancer Res 69: 5433-5440, 2009.

15. Masui K, Tanaka K, Akhavan D, Babic I, Gini B, Matsutani T, Iwanami A, Liu F, Villa GR, Gu Y, et al: mTOR complex 2 controls glycolytic metabolism in glioblastoma through FoxO acetylation and upregulation of c-Myc. Cell Metab 18: 726-739, 2013.

16. Firat $\mathrm{E}$ and Niedermann G: FoxO proteins or loss of functional p53 maintain stemness of glioblastoma stem cells and survival after ionizing radiation plus $\mathrm{PI} 3 \mathrm{~K} / \mathrm{mTOR}$ inhibition. Oncotarget: Jul 19, 2016 (Epub ahead of print).

17. Hanahan D and Weinberg RA: Hallmarks of cancer: The next generation. Cell 144: 646-674, 2011.

18. Clark PM, Mai WX, Cloughesy TF and Nathanson DA: Emerging approaches for targeting metabolic vulnerabilities in malignant glioma. Curr Neurol Neurosci Rep 16: 17, 2016.

19. Liebelt BD, Shingu T, Zhou X, Ren J, Shin SA and Hu J: Glioma stem cells: Signaling, microenvironment, and therapy. Stem Cells Int 2016: 7849890, 2016.

20. Province P, Griguer CE, Han X, Nabors LB and Shaykh HF: Hypoxia, angiogenesis and mechanisms for invasion of malignant gliomas. In: Evolution of the Molecular Biology of Brain Tumors and the Therapeutic Implications. Lichtor T (ed). InTech, Rijeka, 2013.

21. Jensen KS, Binderup T, Jensen KT, Therkelsen I, Borup R, Nilsson E, Multhaupt H, Bouchard C, Quistorff B, Kjaer A, et al: FoxO3A promotes metabolic adaptation to hypoxia by antagonizing Myc function. EMBO J 30: 4554-4570, 2011.

22. Ronellenfitsch MW, Brucker DP, Burger MC, Wolking S, Tritschler F, Rieger J, Wick W, Weller M and Steinbach JP: Antagonism of the mammalian target of rapamycin selectively mediates metabolic effects of epidermal growth factor receptor inhibition and protects human malignant glioma cells from hypoxia-induced cell death. Brain 132: 1509-1522, 2009.

23. Berra E, Benizri E, Ginouvès A, Volmat V, Roux D and Pouysségur J: HIF prolyl-hydroxylase 2 is the key oxygen sensor setting low steady-state levels of HIF-1alpha in normoxia. EMBO J 22: 4082-4090, 2003.

24. Skurk C, Maatz H, Kim HS, Yang J, Abid MR, Aird WC and Walsh K: The Akt-regulated forkhead transcription factor FOXO3a controls endothelial cell viability through modulation of the caspase-8 inhibitor FLIP. J Biol Chem 279: 1513-1525, 2004.

25. Hu MC, Lee DF, Xia W, Golfman LS, Ou-Yang F, Yang JY, Zou Y, Bao S, Hanada N, Saso H, et al: IkappaB kinase promotes tumorigenesis through inhibition of forkhead FOXO3a. Cell 117: 225-237, 2004.

26. Nakamura N, Ramaswamy S, Vazquez F, Signoretti S, Loda M and Sellers WR: Forkhead transcription factors are critical effectors of cell death and cell cycle arrest downstream of PTEN. Mol Cell Biol 20: 8969-8982, 2000.

27. Tran H, Brunet A, Grenier JM, Datta SR, Fornace AJ Jr, DiStefano PS, Chiang LW and Greenberg ME: DNA repair pathway stimulated by the forkhead transcription factor FOXO3a through the Gadd45 protein. Science 296: 530-534, 2002.

28. Brummelkamp TR, Bernards R and Agami R: A system for stable expression of short interfering RNAs in mammalian cells. Science 296: 550-553, 2002.

29. Maurer GD, Tritschler I, Adams B, Tabatabai G, Wick W, Stupp R and Weller M: Cilengitide modulates attachment and viability of human glioma cells, but not sensitivity to irradiation or temozolomide in vitro. Neuro Oncol 11: 747-756, 2009.

30. Henze AT, Riedel J, Diem T, Wenner J, Flamme I, Pouyseggur J, Plate KH and Acker T: Prolyl hydroxylases 2 and 3 act in gliomas as protective negative feedback regulators of hypoxia-inducible factors. Cancer Res 70: 357-366, 2010.

31. Wagenknecht B, Schulz JB, Gulbins E and Weller M: Crm-A, bcl-2 and NDGA inhibit CD95L-induced apoptosis of malignant glioma cells at the level of caspase 8 processing. Cell Death Differ 5: 894-900, 1998

32. Wanka C, Brucker DP, Bähr O, Ronellenfitsch M, Weller M, Steinbach JP and Rieger J: Synthesis of cytochrome $c$ oxidase 2: A p53-dependent metabolic regulator that promotes respiratory function and protects glioma and colon cancer cells from hypoxia-induced cell death. Oncogene 31: 3764-3776, 2012.

33. Dyer BW, Ferrer FA, Klinedinst DK and Rodriguez R: A noncommercial dual luciferase enzyme assay system for reporter gene analysis. Anal Biochem 282: 158-161, 2000.

34. Schneider CA, Rasband WS and Eliceiri KW: NIH Image to ImageJ: 25 years of image analysis. Nat Methods 9: 671-675, 2012. 
35. Obexer P, Geiger K, Ambros PF, Meister B and Ausserlechner MJ: FKHRL1-mediated expression of Noxa and Bim induces apoptosis via the mitochondria in neuroblastoma cells. Cell Death Differ 14: 534-547, 2007.

36. Bakker WJ, Harris IS and Mak TW: FOXO3a is activated in response to hypoxic stress and inhibits HIF1-induced apoptosis via regulation of CITED2. Mol Cell 28: 941-953, 2007.

37. Ullah MS, Davies AJ and Halestrap AP: The plasma membrane lactate transporter MCT4, but not MCT1, is up-regulated by hypoxia through a HIF-1alpha-dependent mechanism. J Biol Chem 281: 9030-9037, 2006.

38. Harter PN, Jennewein L, Baumgarten P, Ilina E, Burger MC, Thiepold AL, Tichy J, Zörnig M, Senft C, Steinbach JP et al: Immunohistochemical assessment of phosphorylated mTORC1-pathway proteins in human brain tumors. PLoS One 10: e0127123, 2015.

39. Rong Y, Durden DL, Van MeirEG and Brat DJ: 'Pseudopalisading' necrosis in glioblastoma: A familiar morphologic feature that links vascular pathology, hypoxia, and angiogenesis. J Neuropathol Exp Neurol 65: 529-539, 2006

40. Ghaffari S, Jagani Z, Kitidis C, Lodish HF and Khosravi-Far R Cytokines andBCR-ABL mediate suppression of TRAIL-induced apoptosis through inhibition of forkhead FOXO3a transcription factor. Proc Natl Acad Sci USA 100: 6523-6528, 2003.

41. Modur V,Nagarajan R, Evers BM and Milbrandt J: FOXO proteins regulate tumor necrosis factor-related apoptosis inducing ligand expression. Implications for PTEN mutation in prostate cancer. J Biol Chem 277: 47928-47937, 2002.

42. Warr MR, Binnewies M, Flach J, Reynaud D, Garg T, Malhotra R, Debnath J and Passegué E: FOXO3A directs a protective autophagy program in haematopoietic stem cells. Nature 494 323-327, 2013

43. Biggs WH III, Cavenee WK and Arden KC: Identification and characterization of members of the FKHR (FOX O) subclass of winged-helix transcription factors in the mouse. Mamm Genome 12: 416-425, 2001.

44. Kops GJ and Burgering BM: Forkhead transcription factors: New insights into protein kinase B (c-akt) signaling. J Mol Med (Berl) 77: 656-665, 1999

45. Chong ZZ, Li F and Maiese K: Activating Akt and the brain's resources to drive cellular survival and prevent inflammatory injury. Histol Histopathol 20: 299-315, 2005.

46. Kops GJ, Dansen TB, Polderman PE, Saarloos I, Wirtz KW, Coffer PJ, Huang TT, Bos JL, Medema RH and Burgering BM: Forkhead transcription factor FOXO3a protects quiescent cells from oxidative stress. Nature 419: 316-321, 2002.

47. Steinbach JP, Wolburg H, Klumpp A, Probst H and Weller M: Hypoxia-induced cell death in human malignant glioma cells: Energy deprivation promotes decoupling of mitochondrial cytochrome $c$ release from caspase processing and necrotic cell death. Cell Death Differ 10: 823-832, 2003.

48. Yoshioka K, Takahashi H, Homma T, Saito M, Oh KB, Nemoto $\mathrm{Y}$ and Matsuoka $\mathrm{H}$ : A novel fluorescent derivative of glucose applicable to the assessment of glucose uptake activity of Escherichia coli. Biochim Biophys Acta 1289: 5-9, 1996.

49. Ramaswamy S, Nakamura N, Sansal I, Bergeron L and Sellers WR: A novel mechanism of gene regulation and tumor suppression by the transcription factor FKHR. Cancer Cell 2: 81-91, 2002.

50. Semenza GL: HIF-1 mediates metabolic responses to intratumoral hypoxia and oncogenic mutations. J Clin Invest 123 3664-3671, 2013

51. Carruthers A, DeZutter J, Ganguly A and Devaskar SU: Will the original glucose transporter isoform please stand up! Am J Physiol Endocrinol Metab 297: E836-E848, 2009.

52. Bhattacharya S, Michels CL, Leung MK, Arany ZP, Kung AL and Livingston DM: Functional role of p35srj, a novel p300/CBP binding protein, during transactivation by HIF-1. Genes Dev 13 : 64-75, 1999.

53. Schwartzenberg-Bar-Yoseph F, Armoni M and Karnieli E: The tumor suppressor p53 down-regulates glucose transporters GLUT1 and GLUT4 gene expression. Cancer Res 64: 2627-2633, 2004.

54. You H, Yamamoto K and Mak TW: Regulation of transactivationindependent proapoptotic activity of p53 by FOXO3a Proc Natl Acad Sci USA 103: 9051-9056, 2006.
55. Loughery J, Cox M, Smith LM and Meek DW: Critical role for p53-serine 15 phosphorylation in stimulating transactivation at p53-responsive promoters. Nucleic Acids Res 42: 7666-7680, 2014.

56. Parsons DW, Jones S, Zhang X, Lin JC, Leary RJ, Angenendt $\mathrm{P}$, Mankoo P, Carter H, Siu IM, Gallia GL, et al: An integrated genomic analysis of human glioblastoma multiforme. Science 321: 1807-1812, 2008.

57. Shi J, Zhang L, Shen A, Zhang J, Wang Y, Zhao Y, Zou L, $\mathrm{Ke} \mathrm{Q}, \mathrm{He} \mathrm{F}$, Wang P, et al: Clinical and biological significance of forkhead class box $\mathrm{O} 3 \mathrm{a}$ expression in glioma: Mediation of glioma malignancy by transcriptional regulation of p27kip1. J Neurooncol 98: 57-69, 2010.

58. Hsu AL, Murphy CT and Kenyon C: Regulation of aging and agerelated disease by DAF-16 and heat-shock factor. Science 300 . 1142-1145, 2003.

59. Yeo H, Lyssiotis CA, Zhang Y, Ying H, Asara JM, Cantley LC and Paik JH: FoxO3 coordinates metabolic pathways to maintain redox balance in neural stem cells. EMBO J 32: 2589-2602, 2013.

60. Ferber EC, Peck B, Delpuech O, Bell GP, East P and Schulze A: FOXO3a regulates reactive oxygen metabolism by inhibiting mitochondrial gene expression. Cell Death Differ 19: 968-979, 2012.

61. Emerling BM, Weinberg F, Liu JL, Mak TW and Chandel NS: PTEN regulates p300-dependent hypoxia-inducible factor 1 transcriptional activity through Forkhead transcription factor $3 \mathrm{a}$ (FOXO3a). Proc Natl Acad Sci USA 105: 2622-2627, 2008.

62. Wanka C, Steinbach JP and Rieger J: Tp53-induced glycolysis and apoptosis regulator (TIGAR) protects glioma cells from starvation-induced cell death by up-regulating respiration and improving cellular redox homeostasis. J Biol Chem 287: 33436-33446, 2012.

63. Riley T, Sontag E, Chen P and Levine A: Transcriptional control of human p53-regulated genes. Nat Rev Mol Cell Biol 9: 402-412, 2008.

64. Kurinna S, Stratton SA, Tsai WW, Akdemir KC, Gu W, Singh P, Goode T, Darlington GJ and Barton MC: Direct activation of forkhead box $\mathrm{O} 3$ by tumor suppressors $\mathrm{p} 53$ and p73 is disrupted during liver regeneration in mice. Hepatology 52: 1023-1032, 2010.

65. Renault VM, Thekkat PU, Hoang KL, White JL, Brady CA, Kenzelmann Broz D, Venturelli OS, Johnson TM, Oskoui PR, Xuan Z, et al: The pro-longevity gene FoxO3 is a direct target of the p53 tumor suppressor. Oncogene 30: 3207-3221, 2011.

66. You H, Jang Y, You-Ten AI, Okada H, Liepa J, Wakeham A, Zaugg K and Mak TW: p53-dependent inhibition of FKHRL1 in response to DNA damage through protein kinase SGK1. Proc Natl Acad Sci USA 101: 14057-14062, 2004.

67. Miyaguchi Y, Tsuchiya K and Sakamoto K: p53 negatively regulates the transcriptional activity of FOXO3a under oxidative stress. Cell Biol Int 33: 853-860, 2009.

68. Fu W, Ma Q, Chen L, Li P, Zhang M, Ramamoorthy S, Nawaz Z, Shimojima T, Wang H, Yang Y, et al: MDM2 acts downstream of p53 as an E3 ligase to promote FOXO ubiquitination and degradation. J Biol Chem 284: 13987-14000, 2009.

69. Wang F, Marshall CB, Yamamoto K, Li GY, Plevin MJ, You H, Mak TW and Ikura M: Biochemical and structural characterization of an intramolecular interaction in FOXO3a and its binding with p53. J Mol Biol 384: 590-603, 2008.

70. Wang F, Marshall CB and Ikura M: Transcriptional/epigenetic regulator $\mathrm{CBP} / \mathrm{p} 300$ in tumorigenesis: Structural and functional versatility in target recognition. Cell Mol Life Sci 70: 3989-4008, 2013.

71. Chan DA, Sutphin PD, Nguyen P, Turcotte S, Lai EW, Banh A, Reynolds GE, Chi JT, Wu J, Solow-Cordero DE, et al: Targeting GLUT1 and the Warburg effect in renal cell carcinoma by chemical synthetic lethality. Sci Transl Med 3: 94ra70, 2011.

72. Horsman MR and Vaupel P: Pathophysiological basis for the formation of the tumor microenvironment. Front Oncol 6: 66, 2016.

73. LaGory EL and Giaccia AJ: The ever-expanding role of HIF in tumour and stromal biology. Nat Cell Biol 18: 356-365, 2016.

74. Weinmann M, Belka C, Güner D, Goecke B, Müller I, Bamberg M and Jendrossek V: Array-based comparative gene expression analysis of tumor cells with increased apoptosis resistance after hypoxic selection. Oncogene 24: 5914-5922, 2005. 